\title{
Analysis on Tourism Demand of Elderly Tourists in Beijing
}

\author{
Qiao Chen \\ Humanities and Social Science College, Beijing Institute of Petrochemical Technology, Beijing, 102167, China
}

\begin{abstract}
Based on 300 questionnaires to Senior Tourists in Beijing, this paper analyzes their based travel demand and the characteristics. And found that there a new form of tourism demand and preferences to elderly tourists, Elderly tourists have clear objectives, hope tour operators to know their ideas, and to provide suitable tourism products, tourist routes and tourism services.
\end{abstract}

Index Terms - Elderly, Tourism demand, Travel behaviors

\section{Introduction}

China's aging population continues to accelerate. "China Aging Development Report (2013) "published in Blue Book pointed out that by the end of 2012, the number of elderly population in China reached 194 million, $14.3 \%$ of the total population. By 2015, the elderly population will reach 202 million, aging rate reaching $14.8 \%$. The aging rate in Beijing is more serious. And some researchers predicted that by 2030 the old population would reach 4.8 million, accounted for $30 \%$. With the improvement of living standards in general, the strong desire to tourism activities of older people is rising. Now tourism has gradually become an important way to enrich the elderly later life, and improve the quality of their lives.

The paper took Beijing as a survey, by questionnaire and interview. It summed up the characteristics of behaviour, preferences about travel information, and access to the channel of travel information of the older. It focused on the attention of tourists travel information of the older, with a view to a deeper understanding of the intrinsic activity of older age group's travel nature, and provided a reference for the tourism business or market development and marketing of tourism information provider.

\section{The Research Methods}

The study was to obtain the required data through questionnaires and on-site interviews. Respondents were over 60 year-old group in Beijing. The sites of survey were one suburb garden and four urban gardens. Questionnaires were given out to the elder at the places where they do morning exercise, including the Daxing District Huangcun Park, Temple of Heaven Park and Changpuhe Park in Dongcheng District, Purple Bamboo Park in Xicheng District and Chaoyang Park in Chaoyang District. The interviews were carried out from 2014 on September 12 to September 27. A total of 300 questionnaires were distributed, 286 of which were recovered. The response rate was $95 \%$. The survey result was real and credible.

Methods of data analysis used here were: Using frequency (Frequency \& Percentage) to analyze the basic and travel characteristics of respondents, The mode of decision- making of tourism, sources of cost, tourism product and the line type preferences, channel of search information.

\section{Result and Analysis}

A. Analysis of Gender, Age Characteristics and Physical Condition.

In the recovery of 286 valid questionnaires, males accounted for $46.43 \%$, women $53.57 \%$, roughly equal proportions. Gender has little effect on the willingness to travel. In terms of age, the persons aged at 60,60 to 65,65 to 70 , and over 70 years old accounted for $25.71 \%, 37.86 \%$, $23.57 \%$, and $12.86 \%$ irrespectively. Most of the interviewees' aged between 60-70 years old usually do morning exercise and are in good health, so the willingness and the proportion to participate in tourism and take into practice was very high. They are the main force of the older tourists in Beijing.

\section{B. The Mode of Decision-Making of Tourism, Sources of their Cost}

This study has shown that elderly tourists like to decide by their own, accounted for $60.93 \%$, By her husband (or wife) to help determine the proportion of $17.99 \%$, children help determine accounted for $14.14 \%$, other such as unit helps determine accounted for $6.94 \%$.

In the travel mode, the respondents who were willing to choose travel agencies accounted for $84.2 \%$. Their purpose was to take a holiday, recuperate and understand the customs everywhere to broaden their horizons but did not want to fatigue and worry about the travel of lodging. Because pure elderly tourist groups were more suitable for his psychological and physical characteristics, so they would give priority to tour organized Sunset Tours. They think it can give them a sense of security [1]. Interviews also showed both short or long distance travel, as well as old age group of tourist organized by travel agency, $56.5 \%$ of the interviewees would more like to travel together with family, close friends or community neighbors. This proved that the elder had high security requirements and would like to travel together with relatives or friends so as to take care each other [2].

Because there the salary guaranteed after retirement, at the same time, some Beijing elderly tourists will have extra investment channels, such as rental housing, stock, so they are more stable income and a surplus.

On travel expense, the proportion of old people own outside of $56.92 \%$, the proportion reached $22.31 \%$ paid by the both sides of husband and wife, paid by children accounted for $16.67 \%$, by the proportion of the relatives and friends to pay 
for Pay $0.77 \%$, other $3.33 \%$. Thus these can be seen, when old people travel, a large part of the cost on their own or the couple pay jointly, this ratio reached $79.33 \%$.

\section{Domestic and Outbound Tourism Time to Choose}

About the traveling days, the elderly persons chose short traveling [3]. This mainly was related to their physical condition, and will not travel too far [3]. There were $41.43 \%$ of the elderly population choosing 3-5 days to travel, indicating that the majority of older people could accept travel within five days. They were more interested in short-term tourist information.

Survey results showed that the elderly was not interested in traveling in the Spring Festival and National Day Golden Week. Most elderly people thought that they could travel all year round, even would like to travel in the offseason, avoiding the tourism season. That was because the elder had more plentiful leisure time, and the concept of having the feast for the New Year at home was comparatively ingrained. Another reason was that they thought they could pay with relatively low prices for the travel in the off-season [4].

\section{Tourist Route and Product Types of Preference}

On domestic tourism route, elderly tourists prefer natural scenery, the evaluation of the mean can reach 4.72; Followed by historical sites, averages 4.37; The third class for national festival, the mean value of 3.67; Shopping tourism class sample mean minimum, only 2.18. On outbound tourism routes, elderly tourists still class for landscape route is most like, the mean value of 4.62; Next to historical sites and ethnic festivals, mean value of 4.24 and 3.60 respectively; Shopping tourism class also lowest, only 2.27. It reflected the elderly would like a beautiful natural environment, fresh air of natural tourist attractions. Selecting the sight spot such as monuments and revolutionary sites for travel has no small commemorative significance in the cultural connotation, which was consistent with the characteristics of older people like nostalgia, so the elderly were quite favored to both types of the attractions.

\section{E. The Reliance of Tourist Information Sources and Way of Use}

There are many ways to spread tourism information, such as word of mouth, magazines, newspaper, radio, television, etc [4]. We can see from Table 1 that $30.71 \%$ older tourist searched information by relatives and family members. This information was mainly relying on oral transmission. This also could explain that the travel agency's reputation was regarded as importance, the elderly put highly trust in recommending or introducing from friends and family. As for this point, the travel agency on the one hand should focus on media coverage and public opinion guidance of the tourism product, and transfer the real and objective information to tourist to improve their credibility. On the other hand tourism enterprises should pay attention to optimizing the quality of tourism services, and strengthen the monitor of the quality of tourism services so that older travelers can get high-quality travel experience.
Secondly, the elderly were more popular to obtain information through the marketing department of a travel agency directly. Through this channel, the information that acquired by the elderly was more targeted. The elder can ask questions face to face, and directly resolve a lot of questions and concerns in the heart. Therefore, travel shops should choose the place where the elder were centralized such as residential, parks, community service stations to carry out various tourism promotion activities to disseminate relevant information.

Thirdly, with the changes in information technology, the popularity of the Internet, more and more people start using the Internet to gather travel information. Network is also the main channel of the elderly to obtain information. This transmission of information can influence extensively the behavior patterns of elderly tourists. But the network message only stayed on the release of information, its guidance role of network was not obvious. With the improvement of the cultural level of the older age groups, more and more older people will be using the Internet. Therefore, functional construction of tourism website should improve as quickly as possible. Publish information as the goal to carry out other tourist services actively, such as travel booking, route advice, guide services, ticketing scheduled and so on. Using of modern information technology and designing virtual reality tour to show out three-dimensional scene of the tourism resources, tourism service facilities, etc. online. By sensory stimulation, the older can intuitively understand the benefits of tourism products.

$\mathrm{TV}$, radio, newspaper have some influence to the elderly [5]. Tourism enterprises, tourist attractions and scenic spots can get through television, radio and informative programs rather than simply advertisement to publish travel information. So it can spread travel information and improve corporate reputation. When travel agency does the product marketing, it can choose the newspapers which the elderly more like, and design propaganda prints that meet with thinking and reading habits of the elderly. Travel agency can use deep newspapers, magazines, books widely to introduce the history, geography, culture, etc. of deep travel information to appeal the older tourists and breed potential customers.

\section{F. Analysis of the Attention for Travel Information}

Tourist information has a very important impact on travel decisions of the elderly. In the respondents, there were $37.14 \%$ of them had travel experience, and $62.86 \%$ did not have. In the attention of the tourist information, there were $62.14 \%$ of the elderly people who were often concerned about the tourist information, but $37.86 \%$ were not. Surveys and interviews showed that $86.6 \%$ of the elder made travel decisions by focusing on the search for tourism information. Among them, $65.3 \%$ get information through a travel agent and travel. For the attention of investigation, we can use a 5-point scale to measure, " 1 " means "not very concerned" and "5" means "very concerned." Analysis to Table 2, the former five of tourist information content that the elderly tourists most concern were: price information $($ Mean $=4.3667)$, tourist route (Mean 
$=4.1933)$, accommodation conditions $($ Mean $=4.08)$, attractions $($ Mean $=4.0667)$ and traffic information $($ Mean $=$ 4.04). It is thus clear that among the tourist information, pricing information, tourist route, accommodations conditions, scenic spot introduction and transportation information were essential foundation of tourism products in tourism activities. And the elder paid the most attention to those information before their travel decision-making, and then the weather conditions, customs, specialty food, specialty recommend and entertainment facilities.

Price information is directly related to tourism consumption of the travel activities. For old people whose psychological is maturity and have rich experience, they usually can consume rationally when they make decision to travel. They were sensitive consumers and tend to choose "value for money" thing in tourism consumption. So pricing information was a greater impact on their travel decisions [6].

On tourism routes, according to their own experience respondents would point out the deficiencies for the tourism routes products which were offered from most travel agencies. The product was uniformity, lack of features, poor of specialization, tight scheduling and so on. Many scenic design projects were for young people, older people lacked the project that they could participate in. Considering the older age groups are more in emergency situations when traveling, the on-site emergency processing demands particularly strict. The product of tourism routes that they expect must reflect the special care for the elderly, such as having professional medical personnel to accompany throughout the travel and the diet is conformed to the characteristics of the elder's stomach.

In accommodation, the elder were more concerned whether the room is clean, comfort and quiet or not. In attractions arrangements they expect tourism activity is flexible, suitable rhythm and more in line with the physical and physiological characteristics of the elderly.

In the choice of transport, although the safety of the aircraft is high, but most old people have high blood pressure, heart diseases, $46.43 \%$ of them preferred to the choice of the train as the transportation media, and $35 \%$ would choose the aircraft. The speed of ship is relatively slow, the proportion choose the ship was lower. Only $7.14 \%$ chose the car to travel was owed to its relatively low safety.

Older people's attention on entertainment was low, only $2.14 \%$ showing that the elderly were not particularly interested in entertainment projects in travel. In shopping, interviewees said they liked to buy good value and substantial souvenirs, but little conspicuous consumption. They also would not like to pursue the luxuries even if their children paid the travel costs for them.

\section{Conclusions}

Older consumers have higher expectations on tourism products. They would most want to travel agencies provide convenient travel routes and products. In addition, they hope to get a deeper experience of tourism, better quality and diversified products.
The elderly access to tourism information was mainly through their children and relatives and friends, which was their most trusted way. Therefore, the operators and managers of tourism enterprises should clearly realize the vast potentials of aged tourist market, pay attention to the effect of word of mouth. First of all, Tourism enterprises can effectively promote the tourism destination by children and relatives and friends, regularly provide filial piety of tourism products. When the elderly go to consult the travel agency, the tourism information of accommodation, catering, transportation, sightseeing, shopping and, itinerary and tour guide services must be provided true, reliable and comprehensive. Secondly, tourism enterprises should make good use of the Internet, further strengthen the elderly tourism information release and spread. So, it can reduce the cost of search tourism information to the elderly.

There is no doubt that with the improvement of national welfare system, the increase of paid vacation, the future of China's tourism market, which companies keen touch and catering to the travel demand of the elderly consumer groups, will grasp the future of the Chinese tourism market, Canny tourism operators should improve their own service specification and process and obtain lucrative market returns.

\section{Acknowledgment}

This research was supported by 2015 The Foundation for The Development Research Base of Modern Industrial District in Beijing.

\section{References}

[1] Yeqin Fu, Xiangmi.Zheng. Research on the tourism motivation, tourism experience of elderly travelers in Sanya. Journal of Hainan Normal University (Natural Science),vol.24, No.4, pp62-468,2011.

[2] Mingying Liang.Investigation and analysis of influence of tourism information transfer ways for tourist behavior patterns: A case study of Mountain Tai. Journal of Taishan University, vol.29,No.1, pp101-105, 2007.

[3] Jang S, Wu C. Seniors' travel motivation and the influential factors: an examination of Taiwanese seniors. Tourism Management, vol.27,No.2, pp306-316,2006

[4] Junyi Li, Min Yang. Research on internet information search behaviors of domestic tourists. Economic Geography, vol.30,No.7, pp1212-1216 (2010).

[5] Amit Bhatnagar, Sanjoy Ghose. Online information search termination patterns across product categories and consumer demographics. Journal of Retailing,vol. 80,No.3, pp221-228,2004

[6] Faranda W T, Schmidt S L.Segmentation and the senior traveler:Implications for today's and tomorrow's aging consunmer.Journal of Travel \& Tourism Marketing,vol. 8,No.2, pp3 -27,1999 